\title{
Different imaging techniques for the detection of pelvic lymph nodes metastasis from gynecological malignancies: a systematic review and meta-analysis
}

\author{
Yi Gong ${ }^{1, *}$, Qingming Wang ${ }^{2, *}$, Li Dong ${ }^{3}$, Yiping Jia ${ }^{4}$, Chengge Hua ${ }^{5}$, Fanglin $\mathrm{Mi}^{6}$ and \\ Chunjie Li ${ }^{7}$ \\ ${ }^{1}$ Department of Obstetrics and Gynaecology, The First Affiliated Hospital of Nanchang University, Nanchang, Jiangxi, China \\ 2 Department of Hematology, The Second Affiliated Hospital of Nanchang University, Nanchang, Jiangxi, China \\ ${ }^{3}$ Department of Cardiology, The Second Affiliated Hospital of Southwest Medical University, Lu Zhou, Sichuan, China \\ ${ }^{4}$ Department of Ultrasound, No.4 West China Teaching Hospital, Sichuan University, Chengdu, China \\ ${ }^{5}$ Department of Oral and Maxillofacial Surgery, Department of Evidence-based Dentistry, West China Hospital of Stomatology, \\ State Key Laboratory of Oral Diseases, Sichuan University, Chengdu, China \\ ${ }^{6}$ Department of Stomatology, Affiliated Hospital of North Sichuan Medical College, Nanchong, Sichuan, China \\ 7 Department of Head and Neck Oncology, Department of Evidence-based Dentistry, West China Hospital of Stomatology, \\ State Key Laboratory of Oral Diseases, Sichuan University, Chengdu, China \\ * These authors are co-first authors of this article \\ Correspondence to: Fanglin Mi, email: 1498092988@qq.com
}

Chunjie Li, email: lichunjie@scu.edu.cn

Keywords: imaging technique; pelvic lymph node; metastasis; gynecological malignance; systematic review and meta-analysis Received: August 02, $2016 \quad$ Accepted: October 22, $2016 \quad$ Published: October 27, 2016

\section{ABSTRACT}

Objective: This study aimed to evaluate the diagnostic performance of different imaging techniques and the corresponding diagnostic criteria for preoperative detection of pelvic lymph node metastasis from gynecological carcinomas.

Methods: Six databases were systematically searched for retrieving eligible studies. Study inclusion, data extraction and risk of bias assessment were performed by 2 reviewers independently. STATA 14.0 was used to perform the meta-analysis. Results: Eighty eligible studies were collected. The pooled sensitivity, specificity, and area under curve (AUC) of CT, MRI and DWI were 47\%, 93\%, $0.7424 ; 50 \%, 95 \%$, 0.8039 and $84 \%, 95 \%, 0.9523$ respectively. As regards PET, PET-CT and US, the pooled sensitivity, specificity and AUC were 56\%, 97\%, 0.9592; 68\%, 97\%, 0.9363 and $71 \%, 99 \%, 0.9008$ respectively. The summary receiver operating characteristic (SROC) curve indicated that the systematic diagnostic performances of PET, PET-CT, DWI were superior to other imaging modalities.

Conclusions: The present work demonstrated that DWI, PET, PET-CT were the top-priority consideration of imaging modalities for detecting metastatic pelvic lymph node in gynecological carcinoma. DWI was recommended as the first choice for metastasis exclusion and all the other imaging techniques including CT and MRI were suitable for metastasis conformation. However, for the early stage lymph node malignancy, PET or PET-CT could represent a better choice. More studies exploring the diagnostic efficacy of detailed criteria are required in the future.

\section{INTRODUCTION}

Gynecological carcinoma, including uterine cervix cancer, uterine corpus cancer, uterine endometrial cancer and ovarian cancer, is one of the leading causes of cancer death among women [1]. Pelvic lymph nodes metastasis is associated with poor clinical outcome in gynecological cancer patients [2]. In addition, the presence of metastatic lymph nodes strongly influences the option of treatment modalities including the necessity or extent of pelvic 
lymph node dissection [3, 4]. Therefore, it is of utmost importance to distinguish the normal pelvic lymph nodes from the metastatic ones before operation.

To assess the involvement of pelvic lymph nodes by gynecological carcinoma, several imaging techniques including magnetic resonance imaging (MRI), computed tomography (CT), positron emission tomographycomputed tomography (PET-CT), were employed in preoperative lymph node inspection [5-7]. However, the accuracy of these imaging modalities is inconstant, as shown by different reports [8, 9]. On the other hand, criteria adopted in the evaluation of lymph node metastasis are inconsistent. Therefore, the current meta-analysis was performed to determine the diagnostic efficacy of imaging modalities employed in detection of pelvic lymph node metastasis from gynecological carcinomas and corresponding diagnostic criteria.

\section{RESULTS}

\section{Results of the search}

We retrieved 613 records by electronic search and hand-searching after removing duplicates. We identified 104 potential eligible studies and we obtained the full-text of these studies. Finally, 80 studies fulfilled the inclusion criteria were included [10-89] (Figure 1).

\section{Characteristics of included studies}

The 80 included studies involved 5817 participants in the age range of 12-94 years. All the participants were diagnosed as gynecological cancers. The imaging modalities used in the included studies were MRI, diffusion weighted imaging (DWI), CT, PET, PET-CT and Ultrasonography (US). The analysis units used were lymph node, anatomical region, hemipelvic and patient. As regards the clinical significance, the analytical unit including anatomical regions, hemipelvic and patient were considered as region/patient unit in the subsequent analysis and we only chose region/patient as unit of analysis when multiple analytical units were eligible. As regards the study design, 33 were prospective and the others were retrospective. A detailed description of the characteristics of each included study is listed in Table 1.

\section{Quality of included studies}

The risk of bias assessment revealed that 19 studies had low risk of bias and 56 had unclear risk of bias; the remaining five had high risk of bias. Driscoll 2015[28] included only MRI negative patients who underwent PETCT examination, which was considered as high risk of inappropriate exclusion. For Yeh 2002 [87], the authors used the criteria that only MRI negative patients could be

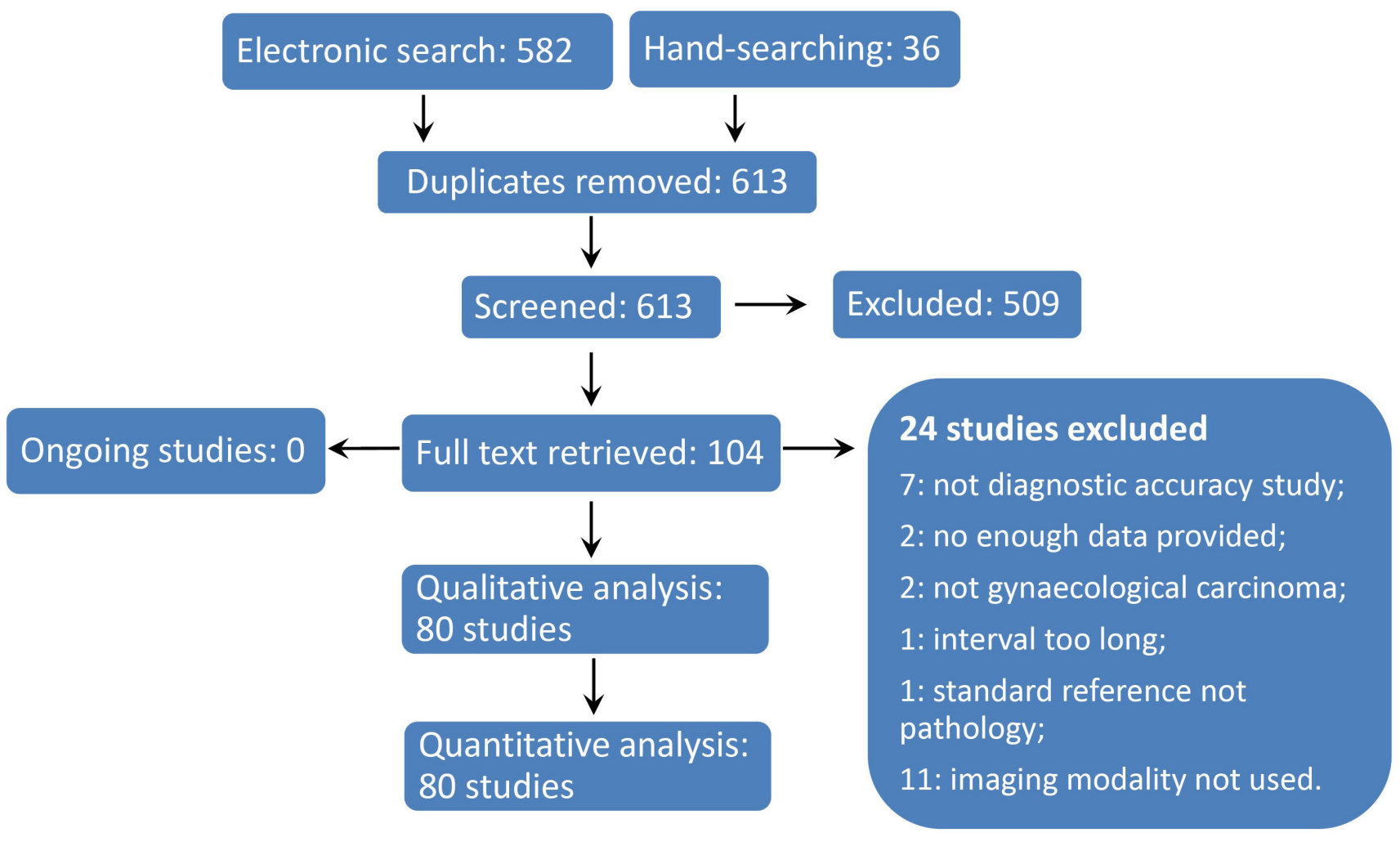

Figure 1: Flow Diagram of Study Inclusion 
Table 1: Characteristics of Included Studies

\begin{tabular}{|c|c|c|c|c|c|c|c|c|}
\hline Study ID & \begin{tabular}{|l|} 
Country/ \\
Region \\
\end{tabular} & Study type & $\mathrm{N}$ & Age & Types of cancer & \begin{tabular}{|l|}
$\begin{array}{l}\text { Targeted lymph } \\
\text { nodes }\end{array}$ \\
\end{tabular} & Unit of analysis & Imaging \\
\hline Antonsen 2013 [10] & Denmark & $P$ & $268^{*}$ & $65(29-94)$ & Endometrial cancer & PLN/PALN & Patient & PET-CT \\
\hline Bandy 1985 [11] & USA & $\mathrm{R}$ & 44 & - & Carcinoma of cervix & PLN/PALN & Patient & $\mathrm{CT}$ \\
\hline Boonya-ussadorn 2014 [12] & Thailand & $\mathrm{R}$ & 33 & 53.7 & Endometrial cancer & PLN & Patient/Region & $\begin{array}{l}\text { PET-CT, CT/ } \\
\text { MRI }\end{array}$ \\
\hline Cabrita 2008 [13] & Portugal & $P$ & 162 & 64.6(22-94) & Endometrial carcinoma & PLN & Patient & MRI \\
\hline Camilien 1988 [14] & USA & $\mathrm{R}$ & 51 & - & Carcinoma of cervix & PLN/PALN & Patient & $\mathrm{CT}$ \\
\hline Chao 2006 [15] & Taiwan & $\mathrm{P}$ & 49 & $55(30-81)$ & Endometrial cancer & PLN/PALN & Region & PET, CT/MRI \\
\hline Chen 2011-a [16] & China & $P$ & 61 & $46(25-60)$ & Uterine cervical cancer & PLN & Node & MRI, DWI \\
\hline Chen 2011-b [17] & China & $P$ & 26 & $35(26-58)$ & Cervical carcinoma & PLN & Node & DWI \\
\hline Chen 2016 [18] & China & $\mathrm{R}$ & 33 & $50.3(28-69)$ & Endometrial cancer & PLN & Patient & MRI \\
\hline Cheng 1999 [19] & Taiwan & $\mathrm{P}$ & 104 & 50.6 & Carcinoma of Cervix & PLN & Patient & TVS \\
\hline Cheung 1998 [20] & Hong Kong & $P$ & $32 *$ & $45(21-64)$ & Cervical cancer & PLN & Patient & LS, CT \\
\hline Choi 2006-a [21] & Korea & $P$ & 22 & $50(25-65)$ & Uterine cervical carcinoma & PLN/PALN & Patient/Region & MRI, PET-CT \\
\hline Choi 2006-b [22] & Korea & $\mathrm{R}$ & 55 & $48(18-65)$ & Uterine cervical cancer & PLN/PALN & Region/Node & MRI \\
\hline Chou 2006 [23] & Taiwan & $\mathrm{P}$ & 60 & $48(28-75)$ & Cervical cancer & PLN & Patient & PET \\
\hline Chung 2007 [24] & Korea & $R$ & 119 & $50(28-81)$ & Cervical cancer & PLN/PALN & Patient/Region & MRI \\
\hline Chung 2009 [25] & Korea & $\mathrm{R}$ & 34 & $45.5(28-70)$ & Cervical cancer & PLN & Patient/Region & PET-CT \\
\hline Chung 2010 [26] & Korea & $\mathrm{R}$ & 83 & $47(24-80)$ & Cervical cancer & PLN/PALN & Patient & MRI, PET-CT \\
\hline Crivellaro 2013 [27] & Italy & $P$ & 76 & $62.9(27-86)$ & Endometrial cancer & PLN/PALN & Patient/Region & PET-CT \\
\hline Driscoll 2015 [28] & Ireland & $\mathrm{R}$ & 47 & $48(22-86)$ & Uterine cervical cancer & PLN & Patient & PET-CT \\
\hline Greco 1989 [29] & UK & $\mathrm{R}$ & 46 & - & Cervical carcinoma & PLN & Patient & MRI \\
\hline Grumbine 1981 [30] & USA & $\mathrm{R}$ & 24 & - & Cervical cancer & PLN & Patient & CT \\
\hline Han $2010[31]$ & Korea & $R$ & $300^{*}$ & - & Endometrial cancer & PLN & Patient & $\mathrm{CT} / \mathrm{MRI}$ \\
\hline Hawighorst 1998 [32] & Germany & $P$ & 33 & $55(20-68)$ & Uterine cervical cancer & PLN & Patient & MRI \\
\hline Hawnaur 1994 [33] & UK & $\mathrm{R}$ & $50 *$ & $18-55$ & Carcinoma of cervix & PLN & Patient/Node & MRI \\
\hline Henrich 2007 [34] & Germany & $P$ & 39 & 61.5(38-87) & Ovarian cancer & PLN & Patient & TVS \\
\hline Horowitz 2004 [35] & USA & $P$ & 19 & $66(54-90)$ & Uterine corpus cancer & PLN/PALN & Patient/Region & PET \\
\hline Huang 2011 [36] & China & $\mathrm{R}$ & 196 & $50.3(28-69)$ & Endometrial cancer & PLN & Patient & DWI \\
\hline Husby 2015 [37] & Norway & $P$ & 102 & - & Endometrial carcinoma & PLN & Patient & PET-CT \\
\hline Inubashiri 2009 [38] & Korea & $R$ & 46 & $56(37-87)$ & Uterine corpus cancer & PLN & Patient/Region & PET, CT, MRI \\
\hline Janus 1989 [39] & USA & $P$ & 22 & $25-66$ & Cervical carcinoma & PLN & Patient & CT, MRI \\
\hline Keller 2004 [40] & Switzerland & $P$ & $13 *$ & 51 & $\begin{array}{l}\text { Cervical/Endometrial/Vulvar } \\
\text { cancer }\end{array}$ & PLN & Patient & MRI \\
\hline Kim 1990 [41] & Korea & $P$ & 30 & $48(31-70)$ & Uterine cervical carcinoma & PLN & Region & CT, MRI \\
\hline Kim 1993 [42] & Korea & $R$ & 99 & $48(27-71)$ & Uterine cervical carcinoma & PLN & Hemi-pelvic & CT, MRI \\
\hline Kim 1994 [43] & Korea & $\mathrm{R}$ & 136 & $49(26-71)$ & Uterine cervical cancer & PLN & Hemi-pelvic & MRI \\
\hline Kim 2008 [44] & Korea & $\mathrm{R}$ & 125 & 48 & Uterine cervical cancer & PLN & Patient/Region & DWI \\
\hline Kim 2011 [45] & Korea & $R$ & 143 & $48(24-73)$ & Uterine cervical cancer & PLN & Node & MRI, DWI \\
\hline Kitajima 2008 [46] & Japan & $P$ & 40 & $56(43-77)$ & Endometrial cancer & PLN/PALN & Patient/Node & PET-CT \\
\hline Kitajima 2013 [47] & Japan & $\mathrm{R}$ & 30 & $62.4(30-88)$ & Endometrial cancer & PLN & Patient & $\begin{array}{l}\text { PET-MRI, } \\
\text { PET-CT,MRI }\end{array}$ \\
\hline Klar 2010 [48] & Germany & $P$ & 13 & - & Uterine corpus cancer & PLN/PALN & Patient & PET \\
\hline Klerkx 2012 [49] & Netherlands & $P$ & 68 & - & Early stage cervical cancer & PLN & Region & MRI, DWI \\
\hline Koplay 2014 [50] & Turkey & $R$ & 58 & $58(42-78)$ & Endometrial cancer & PLN & Patient & DWI \\
\hline Li 2011-a [51] & China & $\mathrm{R}$ & 42 & $49(39-67)$ & Cervical/Endometrial cancer & Internal iliac & Patient & TVS \\
\hline Li 2011-b [52] & China & $\mathrm{R}$ & 62 & $51(35-65)$ & Cervical/Endometrial cancer & Obturator & Patient & TVS \\
\hline
\end{tabular}




\begin{tabular}{|c|c|c|c|c|c|c|c|c|}
\hline Liao 2008 [53] & China & $P$ & 53 & $45(25-59)$ & Cervical carcinoma & PLN & Node & MRI, DWI \\
\hline Liu 2011 [54] & China & $\mathrm{R}$ & 42 & $45.3(30-62)$ & Uterine cervical cancer & PLN & Node & MRI, DWI \\
\hline Lv 2015 [55] & China & $\mathrm{R}$ & 87 & $55(45-73)$ & Cervical cancer & PLN & Patient/Node & PET-CT, MRI \\
\hline Ma 2009 [56] & China & $\mathrm{R}$ & 275 & $21-70$ & Uterine cervical carcinoma & PLN & Hemi-pelvic & $\mathrm{CT}$ \\
\hline Matsukuma 1989 [57] & Japan & $\mathrm{R}$ & 70 & - & Carcinoma of cervix & PLN/PALN & Patient/Region & $\mathrm{CT}$ \\
\hline Nakamura 2010 [58] & Japan & $\mathrm{R}$ & 44 & $60.5(47-87)$ & Endometrial cancer & PLN & Patient & PET-CT \\
\hline Nakamura 2011 [59] & Japan & $\mathrm{R}$ & 106 & $59.32(34-87)$ & Endometrial cancer & PLN & Patient & PET-CT \\
\hline Nogami 2014 [60] & Japan & $R$ & 123 & - & Cervical/Endometrial cance & PLN & Patient & PET-CT \\
\hline Ozalp 1999 [61] & Turkey & $P$ & 37 & $54.3(12-75)$ & Ovarian/endometrial cancer & PLN/PALN & Patient & $\mathrm{CT}$ \\
\hline Park 2008 [62] & Korea & $\mathrm{R}$ & 53 & $52(27-68)$ & Uterine corpus cancer & PLN/PALN & Patient/Region & PET-CT, MRI \\
\hline Picchio 2010 [63] & Italy & $\mathrm{R}$ & $32 *$ & $61(35-79)$ & Endometrial cancer & PLN & Patient & PET-CT \\
\hline Rechichi 2013 [64] & Italy & $\mathrm{R}$ & 40 & $56(45-69)$ & Endometrial cancer & PLN & Region & DWI, MRI \\
\hline Reinhardt 2001 [65] & Germany & $P$ & 35 & $49(26-78)$ & Cervical cancer & PLN, PALN & Patient/Region & MRI, PET \\
\hline Rizzo 2014 [66] & Italy & $\mathrm{P}$ & 217 & 46.2 & Cervical cancer & PLN & Region & MRI \\
\hline Sawicki 2003 [67] & Poland & $P$ & 90 & 63.3(32-86) & Endometrial cancer & PLN & Patient & TVS \\
\hline Signorelli 2009 [68] & Italy & $P$ & 37 & 61(59-78) & Endometrial cancer & PLN & Patient/Region & PET-CT \\
\hline Signorelli 2013 [69] & Italy & $\mathrm{P}$ & 68 & $42(16-91)$ & Ovarian cancer & PLN/PALN & Patient/Region & PET-CT \\
\hline Sironi 2006 [70] & Italy & $\mathrm{P}$ & 47 & $(29-71)$ & Cervical cancer & PLN & Patient & PET-CT \\
\hline Subak 1995 [71] & USA & $\mathrm{R}$ & $79 *$ & $53.3(29-82)$ & Cervical cancer & PLN & Patient & CT, MRI \\
\hline Sufian 2014 [72] & Pakistan & $\mathrm{R}$ & 48 & $55(20-79)$ & $\begin{array}{l}\text { Carcinoma endometrium, } \\
\text { Cervix or ovary cancer }\end{array}$ & PLN & Node & MRI \\
\hline Suga 2011 [73] & Japan & $\mathrm{R}$ & $40^{*}$ & $56(27-81)$ & Endometrial cancer & PLN/PALN & Patient/Region & PET/PET-CT \\
\hline Sugiyama 1995 [74] & Japan & $\mathrm{R}$ & 95 & - & Ovarian cancer & PLN/PALN & Patient & $\mathrm{CT}$ \\
\hline Suzuki 2007 [75] & Japan & $P$ & 30 & $55.4(27-73)$ & Endometrial cancer & PLN/PALN & Patient & PET, CT/MRI \\
\hline Teng 2015 [76] & China & $\mathrm{R}$ & 167 & $57.9(34-80)$ & Endometrial carcinoma & PLN & Patient & MRI \\
\hline Unger 2005 [77] & USA & $\mathrm{R}$ & 13 & $40.8(33.6-48)$ & Cervical cancer & PLN & Patient & PET, CT \\
\hline Van Engelshoven 1984 [78] & Netherlands & $\mathrm{R}$ & $56^{*}$ & - & Cervical cancer & PLN & Patient & CT \\
\hline Vas 1985 [79] & USA & $\mathrm{R}$ & $59^{*}$ & $28-91$ & Carcinoma of cervix & PLN/PALN & Patient & $\mathrm{CT}$ \\
\hline Vijaykumar 1995 [80] & India & $R$ & 75 & - & Cervical carcinoma & PLN & Patient & TAS \\
\hline Walsh 1981 [81] & USA & $P$ & $77^{*}$ & $56(30-90)$ & Carcinoma of cervix & PLN & Patient & $\mathrm{CT}$ \\
\hline Wang 2015 [82] & China & $\mathrm{R}$ & 104 & $44.3(21-67)$ & Ovarian malignant tumor & PLN & Patient & PET-CT \\
\hline Wright 2005 [83] & USA & $\mathrm{R}$ & 59 & 43 & Cervical carcinoma & PLN/PALN & Patient/Node & PET \\
\hline Xue 2008 [84] & China & $\mathrm{R}$ & 24 & 37.9 & Carcinoma of cervix & PLN & Node & DWI \\
\hline Yang 1999 [85] & Hong Kong & $P$ & 31 & $45(21-64)$ & Uterine cervical cancer & PLN & Region & LS \\
\hline Yang 2000 [86] & Hon Kong & $P$ & 43 & $46(21-79)$ & Uterine cervical cancer & PLN & $\begin{array}{l}\text { Hemi-pelvic/ } \\
\text { Node }\end{array}$ & CT, MRI \\
\hline Yeh 2002 [87] & Taiwan & $\mathrm{P}$ & 42 & - & Uterine cervical cancer & PLN/PALN & Patient & PET \\
\hline Yoo 2009 [88] & Korea & $R$ & 99 & $49(29-78)$ & Uterine cancer & PLN & Node & MRI \\
\hline Zhang 2014 [89] & China & $\mathrm{R}$ & 125 & $42.51(25-72)$ & Cervical cancer & PLN & Patient & MRI/DWI \\
\hline
\end{tabular}

Abbreviations: P, prospective; R, retrospective; MRI, magnetic resonance imaging; PET, positron emission tomography; CT, computed tomography; DWI, diffusion-weighted imaging; PET-CT, positron emission tomographyplus computed tomography; PLN, pelvic lymph nodes; PALN, para-aortic lymph nodes; TVS, Trans-vaginal ultrasound; LS, Laparoscopic sonography; TAS, Transabdominal Ultrasound; ROI, region of interest; CT/MRI, some patients got CT and others got MRI, mixed data reported with no separate data; MRI/DWI, some patients got DWI and others got MRI, mixed data reported with no separate data; PET/PET-CT, some patients got PET and others got PET-CT, mixed data reported with no separate data

* only part of patients were included in present study. 
Table 2: Meta-regression of MRI on Diagnostic Efficacy

\begin{tabular}{|l|l|l|l|}
\hline Parameter & I-squared $\mathbf{( 9 5 \% C I ) ~}$ & LRT Chi & P value \\
\hline Publication year & $0.00[0.00-100.00]$ & 0.96 & 0.62 \\
\hline Types of studies & $0.00[0.00-100.00]$ & 0.59 & 0.75 \\
\hline Slide thickness & $0.00[0.00-100.00]$ & 0.96 & 0.62 \\
\hline Intersection gap & $0.00[0.00-100.00]$ & 0.53 & 0.77 \\
\hline Enhanced & $12.01[0.00-100.00]$ & 2.27 & 0.32 \\
\hline Combined with DWI & $76.35[48.28-100.00]$ & 8.46 & 0.01 \\
\hline Blind of radiologist & $0.00[0.00-100.00]$ & 1.15 & 0.56 \\
\hline Blind of pathologist & $0.00[0.00-100.00]$ & 1.96 & 0.37 \\
\hline
\end{tabular}

Table 3: Summary of Meta-analysis (Region/Patient as Unit of Analysis)

\begin{tabular}{|c|c|c|c|c|c|c|c|c|}
\hline & $\mathbf{N}^{\#}$ & SEN & SPE & +LR & -LR & DOR & AUC & Q* \\
\hline MRI & 27 & $0.50[0.42,0.57]$ & $0.95[0.92,0.97]$ & $9.20[6.12,13.81]$ & $0.53[0.46,0.62]$ & $17.23[11.10,26.76]$ & $0.8039(0.0435)$ & $0.7427(0.0352)$ \\
\hline DWI & 6 & $0.84[0.54,0.96]$ & $0.95[0.88,0.98]$ & $15.51[5.93,40.57]$ & $0.17[0.05,0.60]$ & $91.80[12.86,655.54]$ & $0.9523(0.0243)$ & $0.9062(0.0506)$ \\
\hline CT & 18 & $0.47[0.39,0.56]$ & $0.93[0.89,0.96]$ & $7.21[4.44,11.70]$ & $0.56[0.48,0.66]$ & $12.81[7.59,21.61]$ & $0.7424(0.0672)$ & $0.6928(0.0523)$ \\
\hline PET & 10 & $0.56[0.34,0.77]$ & $0.97[0.95-0.98]$ & $19.44[8.22,45.97]$ & $0.45[0.26,0.76]$ & $43.23[11.65,160.41]$ & $0.9592(0.0266)$ & $0.9201(0.0605)$ \\
\hline PET-CT & 20 & $0.68[0.56,0.78]$ & $0.97[0.94,0.98]$ & $20.45[11.96,34.97]$ & $0.34[0.24,0.47]$ & $60.99[29.66,125.39]$ & $0.9363(0.0336)$ & $0.8729(0.0401)$ \\
\hline Ultrasound & 8 & $0.71[0.44,0.89]$ & $0.99[0.83,1.00]$ & $45.41[3.63,566.62]$ & $0.29[0.13,0.66]$ & $155.82[8.87,2737.46]$ & $0.9008(0.0859)$ & $0.8354(0.0828)$ \\
\hline MRI or DWI & 1 & 0.72 & 0.86 & & & & & \\
\hline CT or MRI & 4 & $0.51(0.38-0.63)$ & $0.96(0.95-0.98)$ & $11.83(3.38-41.37)$ & $0.53(0.41-0.67)$ & $24.03(5.75-100.42)$ & $0.5545(0.1625)$ & $0.5409(0.1224)$ \\
\hline
\end{tabular}

\#Number of included studies.

Table 4: Subgroup Analysis of US

\begin{tabular}{|l|l|l|l|l|l|}
\hline & $\mathbf{N}^{\#}$ & SEN & SPE & AUC & $\mathbf{Q}^{*}$ \\
\hline Laparoscopic US & 2 & $0.92[0.75,0.99]$ & $1.00[0.94,1.00]$ & & \\
\hline TransvaginalUS & 5 & $0.55[0.44,0.66]$ & $0.82[0.76,0.86]$ & $0.8759(0.1317)$ & $0.8063(0.1317)$ \\
\hline TransabdominalUS & 1 & $0.67[0.38,0.88]$ & $0.78[0.66,0.88]$ & & \\
\hline
\end{tabular}

\#Number of included studies.

included but they also mentioned that radiologists were not blinded, thus inducing a high risk of bias. For Chen 2011-b [17], Liao 2008 [53] and Liu 2011 [54], they had improper exclusion which were considered as high risk of bias. As regards the applicability assessment, 77 studies had low applicability concerns, three with high applicability concerns, because the three studies used two imaging modalities without reporting the diagnostic efficacy of each imaging modality independently (Figure 2).

\section{Diagnostic efficacy of each imaging modality}

MRI. A total of 36 studies assessed the diagnostic efficacy of MRI to identify pelvic metastatic lymph nodes caused by gynecological cancers. Meta-regression was performed to identify any potential clinical and methodological heterogeneity that could alter the outcome. Meta-regression suggested that the use of DWI might have a significant influence on the outcome including summarized diagnostic efficacy $(P=0.01)$ and sensitivity (SEN) $(P=0.00)$ (Table 2, Appendix Table 2 and 3). So we made subgroup analysis instead of combining all MRI studies together.
A number of 31 studies evaluated traditional MRI diagnostic efficacy, with 27 studies reporting the results using region/patient as analytical unit, 8 using lymph node as unit and 4 using both. The meta-analysis based on region/patient as unit of analysis indicated a pooled SEN of 0.50 , specificity (SPE) of 0.95 , area under curve (AUC) of 0.8039 and a $Q^{*}$ of 0.7427 (Figure 3, Table 3). When node was identified as analytical unit, the pooled SEN was 0.52 but SPE reached 0.95 (Appendix Table 4).

Only 11 studies assessed DWI and 6 studies used region/patient as analytical unit and 5 used node as analytical unit. When region/patient was considered as analytical unit, the pooled SEN was 0.84 and SPE was 0.95. In addition, the SROC curve suggested an AUC of 0.9523 and a $Q^{*}$ of 0.9062 (Table 3, Appendix Figure 1). The node-based results are shown in Appendix Table 4.

To confirm the results of meta-regression, we further conducted pair-wise comparison between MRI and DWI on the pooled results. The results showed that as regards SEN, DWI had a significant advantage over MRI $(P=$ 0.0006), while as regards SPE, no difference between the two treatment modalities was detected $(P=1.00)$. Finally, as regards AUC and $Q^{*}$, DWI had a significant advantage over MRI ( $P=0.003$ and 0.007 , respectively). This result also confirmed the meta-regression. 




Figure 2: Summary Qualities of Included Studies 

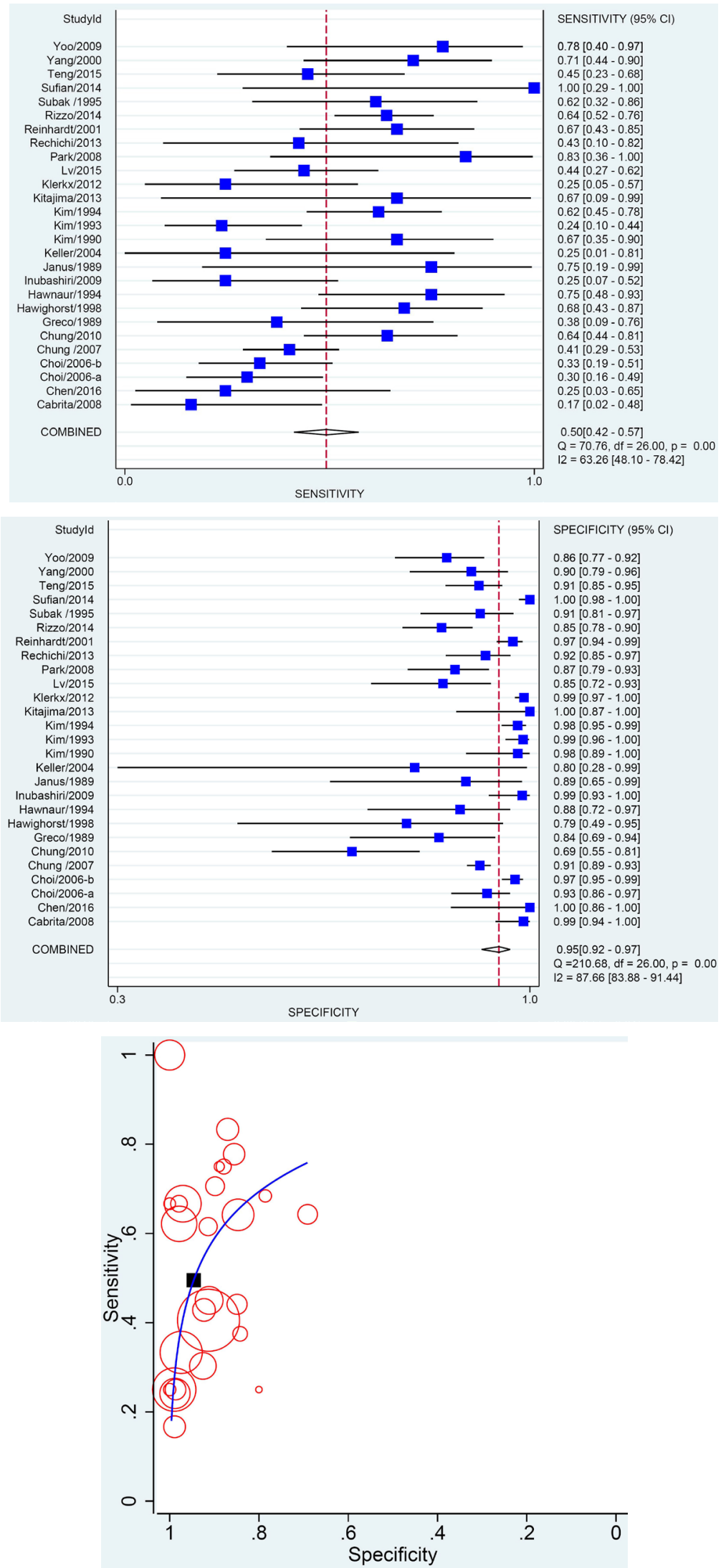

Figure 3: Results of Meta-analysis Assessing Diagnostic Efficacy of MR. A. Pooled SEN; B. Pooled SPE; C. SORC curve. Every circle on the SROC curve represents the coordinate of SEN and SPE in a single study. And the black square represents the summary point where $Q^{*}$ locates. 
Table 5: Diagnostic Efficacy of Different Criteria.

\begin{tabular}{|c|c|c|c|c|c|}
\hline & Criteria & No & Sensitivity & Specificity & AUC (SE) \\
\hline & & 1. $\mathrm{M}$ & & & \\
\hline & $>4 \mathrm{~mm}$ & 2 & $0.78[0.69,0.86]$ & $0.89[0.85,0.92]$ & \\
\hline & $>5 \mathrm{~mm}$ & 2 & $0.58[0.43,0.72]$ & $0.72[0.69,0.75]$ & \\
\hline & $>6 \mathrm{~mm}$ & 2 & $0.50[0.35,0.65]$ & $0.85[0.83,0.88]$ & \\
\hline & $>7 \mathrm{~mm}$ & 2 & $0.46[0.31,0.61]$ & $0.91[0.89,0.93]$ & \\
\hline & $>8 \mathrm{~mm}$ & 5 & $0.60[0.53,0.68]$ & $0.91[0.89,0.93]$ & $0.8071(0.0674)$ \\
\hline Short Axis & $>9 \mathrm{~mm}$ & 2 & $0.33[0.20,0.48]$ & $0.98[0.96,0.99]$ & \\
\hline & $>10 \mathrm{~mm}$ & 18 & $0.47[0.42,0.51]$ & $0.86[0.84,0.87]$ & $0.7164(0.0566)$ \\
\hline & $>10 \mathrm{~mm}$ and/or central necrosis & 1 & $0.45[0.23,0.68]$ & $0.91[0.85,0.95]$ & \\
\hline & $>12 \mathrm{~mm}$ & 1 & $0.35[0.20,0.53]$ & $1.00[0.98 .1 .00]$ & \\
\hline & $>14 \mathrm{~mm}$ & 1 & $0.24[0.12,0.41]$ & $1.00[0.98,1.00]$ & \\
\hline & $>16 \mathrm{~mm}$ & 1 & $0.05[0.01,0.18]$ & $1.00[0.98,1.00]$ & \\
\hline & $>8 \mathrm{~mm}$ & 2 & $0.82[0.72,0.89]$ & $0.47[0.44,0.50]$ & \\
\hline & $>9 \mathrm{~mm}$ & 1 & $0.93[0.82,0.99]$ & $0.66[0.58,0.74]$ & \\
\hline & $>10 \mathrm{~mm}$ & 4 & $0.69[0.56,0.79]$ & $0.84[0.63,0.94]$ & $0.7832(0.0497)$ \\
\hline & $>10 \mathrm{~mm}$ and central necrosis & 1 & $0.18[0.07,0.33]$ & $1.00[1.00,1.00]$ & \\
\hline Long Axis & $>12 \mathrm{~mm}$ & 3 & $0.52[0.39,0.64]$ & $0.87[0.85,0.90]$ & $0.8177(0.1129)$ \\
\hline & $>14 \mathrm{~mm}$ & 3 & $0.45[0.32,0.57]$ & $0.91[0.89,0.93]$ & $0.8133(0.1636)$ \\
\hline & $>16 \mathrm{~mm}$ & 2 & $0.20[0.10,0.34]$ & $0.96[0.94,0.98]$ & \\
\hline & $>18 \mathrm{~mm}$ & 1 & $0.16[0.06,0.32]$ & $1.00[0.98,1.00]$ & \\
\hline & $>20 \mathrm{~mm}$ & 1 & $0.14[0.05,0.29]$ & $1.00[0.98,1.00]$ & \\
\hline & $>0.5$ & 1 & $0.83[0.52,0.98]$ & $0.45[0.40,0.50]$ & \\
\hline & $>0.6$ & 1 & $0.50[0.21,0.79]$ & $0.73[0.68,0.77]$ & \\
\hline Patio (short.long) & $>0.7$ & 2 & $0.64[0.51,0.76]$ & $0.73[0.69,0.77]$ & \\
\hline Kato (snort.1ong) & $>0.8$ & 3 & $0.51[0.40-0.62]$ & $0.87[0.84,0.90]$ & $0.6772(0.0684)$ \\
\hline & $>0.9$ & 1 & $0.08[0.00,0.38]$ & $0.96[0.94,0.98]$ & \\
\hline & $\geq 1.3$ & 1 & $0.47[0.23,0.72]$ & $0.86[0.75,0.94]$ & \\
\hline & Extracapsular spread & 1 & $0.15[0.08,0.26]$ & $1.00[0.96,1.00]$ & \\
\hline & Lobulated & 2 & $0.57[0.34,0.78]$ & $0.83[0.79,0.86]$ & \\
\hline Miscellaneous & Spiculated & 2 & $0.20[0.04,0.48]$ & $0.99[0.97,0.99]$ & \\
\hline iviscenaneous & Indistinct & 1 & $0.00[0.00,0.26]$ & $0.98[0.96,0.99]$ & \\
\hline & \begin{tabular}{|l|} 
Necrosis \\
\end{tabular} & 1 & $0.21[0.12,0.33]$ & $0.94[0.87,0.98]$ & \\
\hline & 4-point grading system & 2 & $0.38[0.25,0.53]$ & $0.93[0.87,0.97]$ & \\
\hline & & 2. D & & & \\
\hline Short Axis & $>10 \mathrm{~mm}$ & 2 & $0.77[0.61,0.89]$ & $0.92[0.87,0.95]$ & \\
\hline & $<0.0005$ & 1 & $0.25[0.05,0.57]$ & $0.93[0.90,0.95]$ & \\
\hline & $<0.00055$ & 1 & $0.25[0.05,0.57]$ & $0.85[0.81,0.88]$ & \\
\hline & $<0.0006$ & 1 & $0.33[0.10,0.65]$ & $0.76[0.71,0.80]$ & \\
\hline & $<0.00065$ & 1 & $0.33[0.10,0.65]$ & $0.74[0.69,0.78]$ & \\
\hline Mean ADC & $<0.0007$ & 1 & $0.75[0.43,0.95]$ & $0.51[0.46,0.56]$ & \\
\hline & $<0.0008$ & 1 & $0.92[0.62,1.00]$ & $0.27[0.23,0.32]$ & \\
\hline & $<0.0009$ & 4 & $0.86[0.79,0.92]$ & $0.79[0.77,0.82]$ & $0.8606(0.1267)$ \\
\hline & \begin{tabular}{|c|}
$<0.00109$ \\
\end{tabular} & 2 & $0.92[0.82,0.98]$ & $0.83[0.78,0.88]$ & \\
\hline & $<0.00115$ & 3 & $0.79[0.71,0.86]$ & $0.82[0.76,0.87]$ & \\
\hline Mean eADC & $>0.335$ & 1 & $0.71[0.57,0.83]$ & $0.73[0.60,0.84]$ & \\
\hline & $<0.000798$ & 1 & $1.00[0.59,1.00]$ & $0.99[0.95,1.00]$ & \\
\hline Minimum $A D C$ & $<0.000807$ & 1 & $1.00[0.59,1.00]$ & $0.98[0.93,1.00]$ & \\
\hline NHInImum ADC & 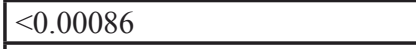 & 2 & $0.89[0.82,0.94]$ & $0.74[0.70,0.77]$ & \\
\hline & $\leq 0.634$ & 1 & $0.93[0.82,0.99]$ & $0.91[0.85,0.95]$ & \\
\hline Max ADC & $<0.00097$ & 1 & $0.79[0.67,0.87]$ & $0.77[0.73,0.80]$ & \\
\hline MIax ADC & $<0.00183$ & 1 & $0.92[0.80,0.98]$ & $0.75[0.62,0.85]$ & \\
\hline Relative $A D C$ & $<0.00028$ & 1 & $0.80[0.69,0.89]$ & $0.72[0.62,0.81]$ & \\
\hline KeTative ADC & $<0.00072$ & 1 & $0.85[0.71,0.94]$ & $0.92[0.86,0.96]$ & \\
\hline
\end{tabular}




\begin{tabular}{|c|c|c|c|c|c|}
\hline \multicolumn{6}{|c|}{ 3. CT } \\
\hline \multirow{2}{*}{ Short Axis } & $>8 \mathrm{~mm}$ & 1 & $0.65[0.38,0.86]$ & $0.81[0.66,0.91]$ & \\
\hline & $>10 \mathrm{~mm}$ & 7 & $0.36[0.29,0.44]$ & $0.93[0.92,0.94]$ & $0.6120(0.0905)$ \\
\hline \multirow{5}{*}{ Long Axis } & $>9 \mathrm{~mm}$ & 1 & $0.71[0.44,0.90]$ & $0.86[0.71,0.95]$ & \\
\hline & $>10 \mathrm{~mm}$ & 2 & $0.63[0.52,0.73]$ & $0.94[0.91,0.96]$ & \\
\hline & $>10 \mathrm{~mm}$ and central necrosis & 1 & $0.27[0.12,0.48]$ & $1.00[1.00,1.00]$ & \\
\hline & $>14 \mathrm{~mm}$ & 5 & $0.41[0.32,0.50]$ & $0.98[0.96,0.99]$ & $0.8331(0.0968)$ \\
\hline & $>20 \mathrm{~mm}$ & 1 & $0.75[0.43,0.95]$ & $0.91[0.75,0.98]$ & \\
\hline Ratio (long:short) & $\geq 1.3$ & 1 & $0.41[0.18,0.67]$ & $0.86[0.71,0.95]$ & \\
\hline Miscellaneous & 4-point grading system & 1 & $0.31[0.11,0.59]$ & $0.99[0.93,1.00]$ & \\
\hline \multicolumn{6}{|c|}{ 4. PET } \\
\hline \multirow{2}{*}{ FDG uptake } & Increased & 5 & $0.57[0.42,0.71]$ & $0.97[0.95,0.99]$ & $0.9370(0.1071)$ \\
\hline & close to primary tumor & 1 & $1.00[0.16,1.00]$ & $1.00[0.72,1.00]$ & \\
\hline \multirow{2}{*}{ Miscellaneous } & 4-point grading system & 1 & $0.31[0.11,0.59]$ & $0.96[0.89,0.99]$ & \\
\hline & 5-point grading system & 1 & $0.60[0.15,0.95]$ & $0.99[0.92,1.00]$ & \\
\hline \multicolumn{6}{|c|}{ 5. PET-CT } \\
\hline FDG uptake & Increased & 13 & $0.54[0.46,0.61]$ & $0.98[0.97,0.98]$ & $0.7498(0.1871)$ \\
\hline \multirow{2}{*}{ SUV } & $>11.0$ & 1 & $0.73[0.54,0.87]$ & $0.93[0.88,0.96]$ & \\
\hline & $>2$ and short $>10 \mathrm{~mm}$ & 1 & $0.91[0.71,0.99]$ & $0.95[0.88,0.99]$ & \\
\hline \multirow{3}{*}{ Max SUV } & $>3.0$ & 1 & $0.71[0.29,0.96]$ & $0.95[0.82,0.99]$ & \\
\hline & $>8.1$ & 1 & $0.83[0.36,1.00]$ & $0.91[0.84,0.96]$ & \\
\hline & $>=2.5$ and short axis $>5 \mathrm{~mm}$ & 1 & $0.69[0.39,0.91]$ & $0.97[0.91,0.99]$ & \\
\hline Miscellaneous & 5-point grading system & 2 & $0.79[0.67,0.88]$ & $0.92[0.87,0.96]$ & \\
\hline
\end{tabular}

In the meta-regression analysis for slide thickness and intersection gap, some including data are unclear. This may influence the result of meta-regression. To eliminate the effect from unclear data, we removed the related studies and conducted pair-wise comparison between $\leq 4 \mathrm{~mm}$ and $>4 \mathrm{~mm}$ subgroup with slide thickness data and $\leq 1 \mathrm{~mm}$ and $>1 \mathrm{~mm}$ subgroup with intersection gap data respectively.

The results showed that as regards SEN, AUC and $Q^{*}$, both slide thickness and intersection gap had no obvious effect on diagnostic performance of MRI ( $P \geq$ $0.05)$. However, as regards SPE, no difference between the two subgroups based on slide thickness was detected $(P=0.34)$ while significant difference was found between the subgroups based on intersection gap $(P<0.0001)$. This result was slightly inconsistent with the result of metaregression on SPE for intersection gap.

\section{CT}

A number of 18 studies investigated the diagnostic efficacy of CT. All of them used region/patient as unit of analysis. Pooled SEN was 0.47 with $95 \%$ CI $[0.39,0.56]$ and SPE was $0.93[0.89,0.96]$. SROC curve indicated an AUC of 0.7424 and Q* of 0.6928 (Table 3, Appendix Figure 2). One study reported the node-based results and is shown in Appendix Table 4.

\section{PET and PET-CT}

Among the included studies, 30 of them reported the diagnostic efficacy of PET and PET-CT. Meta-regression showed that none of the covariates could impact the result (Appendix Table 5-7). As we considered the natural difference of PET and PET-CT, we also made subgroup analysis considering each of them separately. PET subgroup analysis showed a pooled SEN of 0.56 and SPE of 0.97, while PET-CT showed a pooled SEN and SPE of 0.68 and 0.97 , respectively (Table 3, Appendix Figure 3 and 4, node-based results in Appendix Table 4).

We also conducted pair-wise analysis between PET and PET-CT. We used $\mathrm{z}$ test to compare related diagnostic parameters and confirm the results of meta-regression. No difference was found among SEN, SPE, AUC and Q* $(P$ $>0.05$ ).

Nine studies included only patients with an early stage gynecological carcinoma (FIGO stage I/II) (the FIGO stages are: stage 0: carcinoma in situ (common in cervical, vaginal, and vulval cancer); stage I: confined to the organ of origin; stage II: invasion of surrounding organs or tissue; stage III: spread to distant nodes or tissue within the pelvis; stage IV: distant metastasis(es)). The pooled results showed PET or PET-CT had an AUC and $\mathrm{Q}^{*}$ of 0.9152 and 0.8497 , respectively.

US

We retrieved 8 studies focusing on the diagnostic efficacy of US. Meta-analysis indicated a SEN of 0.71 and a SPE of 0.99 (Table 3, Appendix Figure 5, node-based results in Appendix Table 4). A subgroup analysis based on different US techniques was also performed, indicating that laparoscopic US had the highest diagnostic efficacy (Table 4). 


\section{Diagnostic efficacy among different imaging modalities}

To evaluate the diagnostic efficacy of different imaging techniques, we compared SEN, SPE and AUC of the imaging techniques considered. The results showed that DWI had the highest SEN, followed by US and PETCT. As regards SPE, all the imaging techniques had a SPE $>0.90$, with US showing the highest SPE (Table 3). We also combined the SROC curve of all the imaging techniques, and the results showed that MRI and CT had a lower diagnostic efficacy compared to DWI, PET, PET$\mathrm{CT}$ and US (Figure 4). The comparison between AUC and $\mathrm{Q}^{*}$ among all the imaging techniques also indicated that DWI, PET, PET-CT and US had higher AUC and Q* values compared to $\mathrm{CT}$ or MRI (Table 2).

\section{Diagnostic efficacy of different diagnostic criteria}

To detect the diagnostic efficacy of each diagnostic criterion, we summarized and synthesized all the reported criteria used in MRI, DWI, CT, PET, PET-CT studies. The diagnostic efficacy of each criterion used in various imaging techniques was listed in Table 5.

\section{DISCUSSION}

Gynecological malignancy seriously threatens women health life [90]. Involvement of pelvic lymph nodes is one of the most important poor prognostic factors in gynecological malignancy [91-93]. Some studies demonstrated that $10-30 \%$ of women with stage I or II gynecological malignancy had pelvic lymph node metastasis and the probability of lymph node metastasis is even higher when this malignancy reach the stage III and IV, thus significantly impairing the prognosis [94-96]. Preoperative detection of pelvic lymph node metastasis is an important issue for gynecological surgeons, who can modulate the surgical plan and subsequent treatment according to the detection results. However, the achievement of a satisfactory detection is not a simple task. In clinical practice, a number of imaging modalities have been used to evaluate the lymph node status before surgery, including CT, MRI, PET, PET-CT and US [11, $13,15,21,34]$. Nevertheless, diagnostic efficacy of these techniques were reported inconsistently $[21,62,86]$, thus, no unanimous conclusion could be drawn. On the other hand, no study assessed simultaneously all these imaging techniques, thus no study could provide information on which imaging technique had highest diagnostic

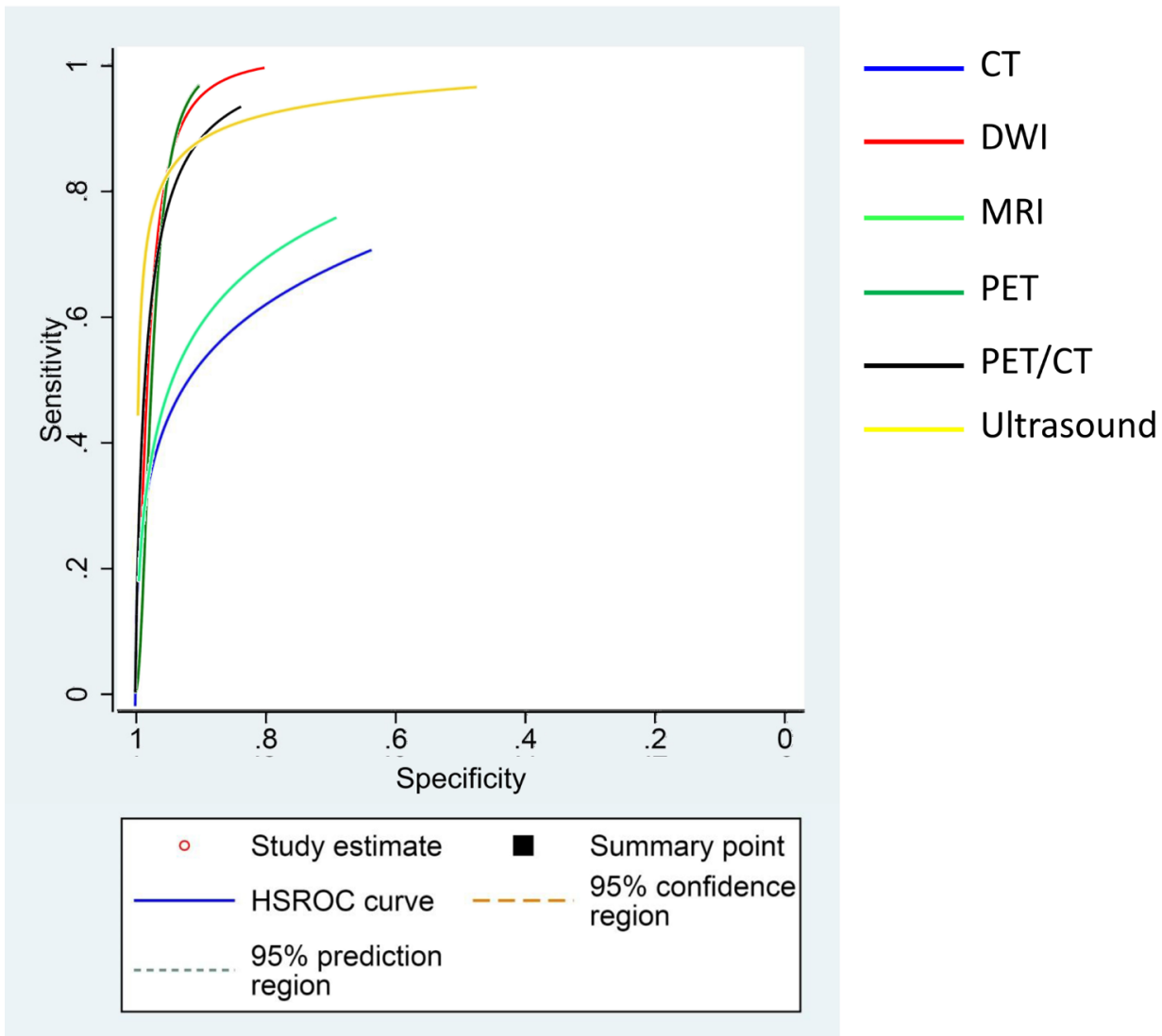

Figure 4: Combination of SROC curves from all kinds of imagings 
efficacy. What's more, the large numbers of relevant papers available confuse the clinicians as they all report different diagnostic criteria. Therefore, we performed this systematic review and meta-analysis to provide clinical evidence for a better selection of preoperative imaging modalities and relevant criteria for the detection of metastatic pelvic lymph node. Furthermore, our study could help clinician to select the best surgical gynecological carcinoma procedure. As far as we know, this is the first meta-analysis systematically evaluating and comparing the diagnostic efficacy of almost all the relevant imaging approaches currently used in pelvic lymph node staging of gynecological malignancy. Besides, this systematic review is also the first one discussing the diagnostic efficacy of relevant criteria for a better evaluation of pelvic lymph node metastasis in gynecological carcinoma.

In this systematic review and meta-analysis, 80 eligible studies were recruited; six imaging modalities were used in these studies including CT, MRI, DWI, PET, PET-CT and US. The results of our study illustrated that the pooled SEN of these imaging techniques for detecting metastatic pelvic lymph nodes were $47 \%$ (CT), 50\% (MRI), 84\% (DWI), 56\% (PET), 68\% (PET-CT), 71\% (US), while the polled SPE ranged from $93 \%$ to $99 \%$ with limited variation, with the highest SPE achieved by US (99\%). The AUC values that represent the systematic diagnostic efficacy were 0.7424 (CT), 0.8039 (MRI), 0.9523 (DWI), 0.9592 (PET), 0.9363 (PET-CT), 0.9008 (US). Scheidler and colleagues [97] reported in 1997 $\mathrm{CT}$ and MRI diagnostic performance in the detection of metastatic pelvic lymph node in cervical cancer with a $Q^{*}$ value of 0.78 and 0.87 , respectively, which are higher than our results. These results have caught our attention to explore why CT and MRI diagnostic performance several decades ago is superior to our results including studies with more advanced equipment. To clarify this issue, we calculated the SEN and SPE using the data provided by Scheidler's, and we obtained a SEN and SPE of 36\% and $94 \%$ for CT, $57 \%$ and $96 \%$ for MRI, respectively, which are close to our result. In Scheidler's study, only 11 CT studies and 9 MRI studies were included, whereas $18 \mathrm{CT}$ studies and 27 MRI studies were included in our study. The higher $\mathrm{Q}^{*}$ value might derived from a relatively smaller number of included study and their heterogeneity. As regards DWI, Shen et al [98] evaluated the diagnostic performance of DWI in cervical cancer metastasis with a SEN, SPE and AUC of $86 \%, 84 \%$ and 0.9384 , respectively. The pooled SEN and AUC are similar to our results, while the SPE of Shen is less than the SPE obtained in the present work. The predominant diagnostic performance of DWI was also confirmed by the result of Metaregression in our study. In Shen's work, all the included studies were from 2 Asian countries (China and Korea), but in our current meta-analysis, we included studies from both Asia and Europe (China, Korea, Netherlands,
Turkey and Italy), being thus more representative. The result suggests that DWI provided a better performance in distinguishing metastatic lymph node from benign lymph node. In addition, Chang et al [99] and Bollineni et al [9] conducted similar systematic reviews exploring diagnostic efficacy of PET and PET-CT in detection of pelvic lymph node metastasis in endometrial cancer, in which pooled SEN, SPE and AUC ranged from $63 \%$ to $72 \%, 94 \%$ to $94.7 \%$ and 0.94 to 0.953 , respectively. Only 7 and 13 studies were included in Chang's and Bollineni's meta-analysis, respectively. Our results were consistent with Chang's and Bollineni's study although we included more studies. However, none of the above mentioned systematic reviews have evaluated all these imaging techniques simultaneously; thus, they could not evaluate which imaging technique has the highest diagnostic efficacy in the detection of pelvic lymph node metastasis from gynecological malignancies. That is exactly what we obtained in our systematic review. Based on the evidence provided by our current study, we suggest clinicians to proceed as follows. First, since DWI had a highest SEN, it represents the best technique for excluding pelvic lymph node metastasis in a patient with gynecological carcinoma. Second, all the imaging techniques we evaluated had a SPE higher than $93 \%$, being suitable for confirming the diagnosis. Third, PET, DWI, PET-CT or US had a higher diagnostic efficacy than CT or MRI, thus they can be chosen as pre-operative scanning.

PET, PET-CT, DWI and US diagnostic efficiency found in the present study were clearly higher than conventional imaging modalities such as MRI or CT. This might be mainly due to the different imaging principles among these modalities. PET or PET-CT is a functional imaging, which relies on the increased fluoro-2-deoxyD-glucose (FDG) uptake of malignant tissue [100]. This metabolism change usually precedes morphological changes, therefore, PET or PET-CT can detect lymph node malignant transformation at a relative early stage compared with MRI or CT, which mainly identify malignant transformation based on morphological changes [65]. In our study, data of 9 recruited studies using PET $[23,65,77,83]$ or PET-CT $[25,26,28,60,70]$ in an early stage gynecological malignancies were combined, 1 study [28] even restricted inclusion criteria with negative MRI findings of metastatic pelvic lymph nodes. Pooled data demonstrated that the AUC and $\mathrm{Q}^{*}$ value were 0.9152 and 0.8497 , respectively, suggesting that PET or PET-CT were more suitable to conventional modalities such as CT (AUC, 0.7424; $Q^{*}, 0.6928$ ) or MRI (AUC, 0.8039; Q*, 0.7427 ) in distinguishing metastatic pelvic lymph nodes in early stage patients.

Compared with radiological modalities, the US, especially transvaginal US, is safer, cost-effective and widely available. In clinical practice, laparoscopic, transvaginal and transabdominal US are frequently used in detection of metastatic lymph node. Among all kinds 
of US, laparoscopic US (number of studies: 2) had the highest SEN and SPE, followed by transvaginal US (number of studies: 5) with an AUC value of 0.8759 . In the 5 transvaginal US studies, 2 of them restricted study objects to internal iliac and obturator lymph nodes which are anatomically close to vagina $[52,101]$. The diagnostic accuracies were significantly higher in these 2 studies $(0.92-0.95)$ than in the other 3 studies $(0.46$ $0.89)$. However, the SPE in 4 of these 5 studies was high (94\%-100\%) [34, 52, 67, 101]. The results suggested that the detection of metastatic pelvic lymph nodes with transvaginal US might result in misdiagnosis, but it might be a good technique to confirm metastatic lymph node.

Since the diagnostic performances achieved by PET, PET-CT or DWI are similar and DWI is less expensive and available, we recommended DWI as the first option for the detection of pelvic lymph node in gynecological carcinoma. Nevertheless, PET or PET-CT might represent the better choice for the detection of micrometastatic lymph node in early stage carcinoma. Additionally, transvaginal US could be considered as a safe and economic technique for diagnosis confirmation of the internal iliac and obturator lymph nodes metastasis.

Furthermore, in this meta-analysis, we analyzed the diagnostic efficacy of each single diagnostic criterion. Size or shape based criterion was frequently used in assessment of lymph node evaluation by CT and MRI. In general, as the diameters of short axis or long axis adopted as positive criteria increase, the SEN decreased as the SPE increase. Therefore, when short axis diameter was adopted as a positive criterion in MRI examination, we recommended a diameter larger than $8 \mathrm{~mm}$ as the best criteria. When long axis criterion was adopted, we recommended a diameter of $12 \mathrm{~mm}$ as the cut-off point. In addition, shape based criteria were also used in discriminating metastatic lymph node from benign disease. Based on the evidence provided by this meta-analysis, the lobulated shape should be preferentially adopted. When CT was used in metastatic lymph node detection, short axis diameter $>8 \mathrm{~mm}$ or long axis diameter $>9-10 \mathrm{~mm}$ was considered. Besides, if necrosis was found in the lymph node, the diagnostic specificity was greatly improved [102]. Criteria used in DWI were also analyzed. Minimum ADC $<0.0008$ was better than mean ADC or relative ADC with a sensitivity of $100 \%$ and specificity between $98 \%$ and $99 \%$. As regards PET, 5-point grading system is recommended. Moreover, SUV $>2$ combined with short axis $>10 \mathrm{~mm}$ is suggested as positive criterion when PET-CT is adopted.

The main results in this meta-analysis were mainly based on patient or region as analytical unit, and nodebased data was not mainly applied. The number of studies using node-based data is much smaller than that using patient/region based data. To a surgeon, the most important issue is to learn whether a certain region in pelvic was invaded by malignant lymph node rather than exactly which lymph node was contaminated. Because in clinical setting, if a malignant lymph node was distinguished by imaging technology preoperatively, all the lymph nodes in the malignant lymph node containing region were considered to be excised. In other words, patient/region based data is of more clinical importance than node-based data. In our study, we combined patient-based data with region-based data together. In clinical practice, when one lymph node in a certain pelvic region is malignant, the patient is considered affected by pelvic lymph node malignancy. Once patient is proved to have pelvic lymph node metastasis, the surgical procedure and the prognosis prediction will be similar. This is why we combine regionbased data with patient-based data in the current study.

Alongside the listed results, some limitations are present in this systematic review. First, limited data on the diagnostic efficacy of a single criterion were retrieved, thus influencing data pooling with a single criterion. We call for that future studies could focus on this issue and more studies exploring diagnostic efficacy of single criterion are required for further exploration of a high diagnostic efficient criterion. Second, some included studies enrolled a small number of patients, which influenced the accuracy of the results. Third, some studies had a high risk of bias and application concern. This should be improved by further conducting of high quality studies in the future. Last but not least, although we have investigated the potential resource of heterogeneity in study-level factors, the influence of other confounding factors such as skill of medical imaging technologists and pathologists, influence of node dissection for pathological examination, quality of imaging machines could not be considered. In the current meta-analysis, the imaging analysis in the majority of including studies were performed by two imaging technologists respectively which may partially offset the heterogeneity derived by judgment difference of imaging technologists. And for the other factors, they are the problems that all diagnostic accuracy systematic reviews meet. Theories should be raised to solve such problems in the future.

In conclusion, our present study demonstrated that DWI, PET, PET-CT were the top-priority consideration as imaging modalities used for detecting metastatic pelvic lymph node in gynecological carcinoma. DWI is recommended as the first choice for metastasis exclusion and all the other imaging techniques, including CT and MRI, were suitable for metastasis conformation. However, for an early stage lymph node malignancy evaluation, PET or PET-CT might be the better choice. More studies exploring the diagnostic efficacy of detailed criteria are required in the future.

\section{MATERIALS AND METHODS}

According to the protocol set in advance, two reviewers (Gong Y, Wang Q) conducted the study inclusion, data extraction, and risk of bias assessment in 
duplicate. Disagreements between the two reviews were solved by discussion.

\section{Inclusion criteria}

Inclusion criteria were established as follows: (1) Types of studies: diagnostic test accuracy studies designed as cohort studies; (2) participants: diagnosed as gynecological cancer including uterine cervical cancer, corpus cancer, ovarian cancer, endometrial carcinoma. All these diagnoses should be confirmed by biopsy or pathology; (3) index tests: all kinds of imaging techniques including MRI, DWI, CT, PET, PET-CT, US; (4) reference standard: pathological diagnosis; and (5) targeting conditions: metastasis of the tumor to the pelvic lymph nodes; (5) outcomes: true positive (TP), false positive (FP), false negative (FN), and true negative (TN) (Other outcome variables such as SEN, SPE, +LR and -LR were also considered as they could help to calculate TP, FP, FN and $\mathrm{TN}$ ).

\section{Search strategy and study inclusion}

Both electronic search and hand-searching were performed for this systematic review.

Bibliographic databases used included MEDLINE (via PubMed, 1946 to March 15th, 2016), EMBASE (via OVID, 1980 to March 15th, 2016), and China National Knowledge Infrastructure (CNKI, 1994 to 1948 to March 15th, 2016). We also performed grey literature searching including Science Paper Online (to 1948 to March 15th, 2016), System for Information on Grey Literature in Europe (OpenSIGLE, 1980 to 2005), and WHO International Clinical Trials Registry Platform (WHO ICTRP, to 1948 to March 15th, 2016). The search strategy of the above databases was designed according to Cochrane Handbook for Diagnostic Accuracy Reviews, draft version 0.4 , with a combination of MeSH terms and free text words [103]. The MeSH terms used included: "Pelvis", "Neoplasms", "Lymph Nodes", and "Sensitivity and Specificity".

We also hand-searched the reference list of all the included studies to retrieve any eligible study missed during the electronic searches.

The two reviewers first scanned the search records (titles and abstracts) and find any potential eligible study. All the recognized records were combined and the full texts of these studies were retrieved. The reviewers further evaluated the full texts and made a final judgment according to the inclusion criteria.

\section{Risk of bias and applicability assessment}

We assessed the risk of bias and applicability using QUADAS-2 and recorded them using Revman 5.3 (Copenhagen, The Nordic Cochrane Centre, The Cochrane Collaboration) [104]. Four domains were included in the assessment tool, such as patient selection, index test, reference standard, and flow and timing. Each domain was assessed in terms of risk of bias, with the first three domains were additionally assessed in terms of concerns regarding applicability. We answered signaling questions provided by QUADAS-2 to evaluate the risk of bias. We tailored the signaling questions to form review-specific guidance as we have done in our previous systematic review assessing cervical node metastasis of head and neck cancer [105].

The signaling questions for this review included:

Patient selection:

Patients enrolled in this study were obtained by a consecutive or random sampling?

Was a case-control design avoided?

Did the study avoid inappropriate exclusions?

Index test:

Were the index test results interpreted without knowledge of the results of the reference standard?

Reference standard:

Was the reference standard likely to correctly classify the target condition?

Were the reference standard results interpreted without knowledge of the results of the index test?

Flow and timing:

Was there an appropriate interval between index tests and reference standard?

Did all patients receive a reference standard?

Were all patients included in the analysis?

The risk of bias for each domain was assessed as high, unclear or low risk of bias. High risk of bias indicated that the answer of at least one signal questions was no; low risk of bias indicated that the answers to all the signal questions in this domain were yes. Unclear risk of bias referred to any situations other than high or low risk of bias. Applicability was also classified as high, unclear or low applicability concerns. The assessment criteria of risk of bias for the whole study were similar to that used in domain evaluation. For all the four domains in a whole study, if the risk of bias for any domains was high, the risk of bias of the whole study would be assessed as high; On the contrary, if all domains had low risk of bias, the risk of bias of the whole study would be assessed as low; any situations other than high or low risk of bias would be assessed as unclear. 


\section{Data extraction}

We developed a formal data extraction form for a diagnostic accuracy of our systematic reviews $[105,106]$, which was used in our previous reviews and pilot-tested on $10 \%$ of the included studies in this review. The content of the data extraction form included: Re-evaluation of eligibility; basic information of the study (authors, title, publication time); characteristics of the participants (age, gender, inclusion criteria, tumor types or location, number of included patients); study location (country, patients source); index test and reference standard (details of different imaging techniques and pathological diagnosis, diagnostic criteria, blinding, and consistency of the radiologists); study design (study types and duration); and outcomes (TP, FP, FN, and TN, or any related parameters useful to calculated these outcomes).

\section{Meta-analysis}

We mainly used Stata 14.0 (Stata Corp, College Station, TX, USA) to perform meta-analysis. Statistical heterogeneity was assessed first to help with effect-model chosen in the analysis. Studies with significant clinical heterogeneity were not pooled. In case of a significant clinical heterogeneity, studies were assessed by metaregression providing evidences for subgroup analysis. We did not assess the reported bias because it was not formally accepted in diagnostic accuracy systematic reviews [107].

\section{Statistical heterogeneity}

The statistical heterogeneity was assessed by $\mathrm{Chi}^{2}$ test with the $\mathrm{I}^{2}$ statistic. A slight statistical heterogeneity was identified when $\mathrm{I}^{2} \geq 0.10$, and fixed-effect model was used for meta-analysis. When $\mathrm{I}^{2}<0.10$, significant statistical heterogeneity was identified and random-effect model was used.

\section{Meta-regression}

Log diagnostic odds ratio (logDOR) was considered as the dependent variable of meta-regression. The assignment for each covariate is shown in Appendix Table 1. Multi-covariates meta-regression was performed for each meta-analysis with more than 10 studies included with $P<0.10$ as statistical significance. Clinical and methodological heterogeneities with potential effects to affect results would undergo subgroup analysis.

\section{Meta-analysis}

The size effect used in the meta-analysis included SEN, SPE, +LR, -LR, DOR, and 95\% CIs. We also draw the SROC curve; AUC and Q* (the point of SROC on which sensitivity was equal to specificity) were calculated to reflect synthesized diagnostic accuracy.

\section{Pair-wise comparison}

When needed, pair-wise comparison was performed using $\mathrm{z}$ test, which could detect diagnostic differences between SEN, SPE, AUC and Q*. The following formula was used: $\mathrm{Z}=(\mathrm{VAL} 1-\mathrm{VAL} 2) / \mathrm{SQRT}(\mathrm{SE} 12+\mathrm{SE} 22)$. VAL indicated the means of SEN, SPE, AUC or Q* and SE was the standard error of the corresponding variables. A value of $P<0.05$ was considered statistically significant.

\section{ACKNOWLEDGMENTS}

This study was supported by grant from Natural Science Foundation of Jiangxi Province, China (20132BAB205004).

\section{CONFLICTS OF INTEREST}

The authors declare that there are no conflicts of interest.

\section{Author contributions}

Yi Gong, Qingming, Wang, conducted the systematic review and meta-analysis including writing the paper; Li Dong was responsible for analysis, tables and figures arrangement, Yiping Jia provided clinical guidance, Chengge Hua, Fanglin Mi and Chunjie Li supervised the conduction of systematic review and meta-analysis and revised the draft.

\section{REFERENCES}

1. Kamura T, Tsukamoto N, Tsuruchi N, Saito T, Matsuyama $\mathrm{T}$, Akazawa K and Nakano H. Multivariate analysis of the histopathologic prognostic factors of cervical cancer in patients undergoing radical hysterectomy. Cancer. 1992; 69:181-186.

2. Lewin SN, Herzog TJ, Medel NIB, Deutsch I, Burke WM, Sun $\mathrm{X}$ and Wright JD. Comparative performance of the 2009 international Federation of gynecology and obstetrics' staging system for uterine corpus cancer. Obstetrics \& Gynecology. 2010; 116:1141-1149.

3. Sakuragi N, Satoh C, Takeda N, Hareyama H, Takeda M, Yamamoto R, Fujimoto T, Oikawa M, Fujino T and 
Fujimoto S. Incidence and distribution pattern of pelvic and paraaortic lymph node metastasis in patients with stages IB, IIA, and IIB cervical carcinoma treated with radical hysterectomy. Cancer. 1999; 85:1547-1554.

4. Michel G, Morice P, Castaigne D, Leblanc M, Rey A and Duvillard P. Lymphatic spread in stage Ib and II cervical carcinoma: anatomy and surgical implications. Obstetrics \& Gynecology. 1998; 91:360-363.

5. Park SO, Kim JK, Kim KA, Park BW, Kim N, Cho G, Choi HJ and Cho KS. Relative apparent diffusion coefficient: determination of reference site and validation of benefit for detecting metastatic lymph nodes in uterine cervical cancer. Journal of Magnetic Resonance Imaging. 2009; 29:383-390.

6. Son H, Kositwattanarerk A, Hayes MP, Chuang L, Rahaman J, Heiba S, Machac J, Zakashansky K and Kostakoglu L. PET/CT Evaluation of Cervical Cancer: Spectrum of Disease 1. Radiographics. 2010; 30:1251-1268.

7. Hricak H, Gatsonis C, Coakley FV, Snyder B, Reinhold C, Schwartz LH, Woodward PJ, Pannu HK, Amendola $\mathrm{M}$ and Mitchell DG. Early invasive cervical cancer: CT and MR imaging in preoperative evaluation-ACRIN/ GOG Comparative study of diagnostic performance and interobserver variability 1 . Radiology. 2007; 245:491-498.

8. Luomaranta A, Leminen A and Loukovaara M. Magnetic resonance imaging in the assessment of high-risk features of endometrial carcinoma: a meta-analysis. Int J Gynecol Cancer. 2015; 25:837-842.

9. Bollineni VR, Ytre-Hauge S, Bollineni-Balabay O, Salvesen HB and Haldorsen IS. High Diagnostic Value of 18F-FDG PET/CT in Endometrial Cancer: Systematic Review and Meta-Analysis of the Literature. J Nucl Med. 2016; 57:879885.

10. Antonsen SL, Loft A, Fisker R, Nielsen AL, Andersen ES, Høgdall E, Tabor A, Jochumsen K, Fagö-Olsen CL and Asmussen J. SUVmax of 18 FDG PET/CT as a predictor of high-risk endometrial cancer patients. Gynecologic oncology. 2013; 129:298-303.

11. BANDY LC, Clarke-Pearson DL, SILVERMAN PM and CREASMAN WT. Computed tomography in evaluation of extrapelvic lymphadenopathy in carcinoma of the cervix. Obstetrics \& Gynecology. 1985; 65:73-76.

12. Boonya-ussadorn T, Choi WH, Hyun J, Kim S, Chung $\mathrm{S}$ and Yoo I. 18F-FDG PET/CT findings in endometrial cancer patients: the correlation between SUVmax and clinicopathologic features. J Med Assoc Thai. 2014; 97:S115-S122.

13. Cabrita S, Rodrigues H, Abreu R, Martins M, Teixeira L, Marques $\mathrm{C}$, Mota F and de Oliveira CF. Magnetic resonance imaging in the preoperative staging of endometrial carcinoma. Eur J Gynaecol Oncol. 2008; 29:135-137.

14. Camilien L, Gordon D, Fruchter RG, Maiman M and Boyce JG. Predictive value of computerized tomography in the presurgical evaluation of primary carcinoma of the cervix. Gynecologic oncology. 1988; 30:209-215.
15. Chao A, Chang TC, Ng KK, Hsueh S, Huang HJ, Chou HH, Tsai CS, Yen TC, Wu TI and Lai CH. 18F-FDG PET in the management of endometrial cancer. Eur J Nucl Med Mol Imaging. 2006; 33:36-44.

16. Chen YB, Liao J, Xie R, Chen GL and Chen G. Discrimination of metastatic from hyperplastic pelvic lymph nodes in patients with cervical cancer by diffusionweighted magnetic resonance imaging. Abdom Imaging. 2011; 36:102-109.

17. Chen YB, Hu CM, Chen GL, Hu D and Liao J. Staging of uterine cervical carcinoma: whole-body diffusion-weighted magnetic resonance imaging. Abdominal imaging. 2011; 36:619-626.

18. Chen M and Liu J. Value of MRI and intraoperative exploration in the diagnosis of myometrial infiltration and lymph node metastasis of endometrial carcinoma. Chinese Journal of Practical Gynecology Obstetrics. 2016; 32:159162.

19. Cheng WF, Wei LH, Su YN, Cheng SP, Chu JS and Lee $\mathrm{CN}$. The possible use of colour flow Doppler in planning treatment in early invasive carcinoma of the cervix. Br J Obstet Gynaecol. 1999; 106:1137-1142.

20. Cheung TH, Yang WT, Yu MY, Lo WK and Ho S. New development of laparoscopic ultrasound and laparoscopic pelvic lymphadenectomy in the management of patients with cervical carcinoma. Gynecol Oncol. 1998; 71:87-93.

21. Choi HJ, Roh JW, Seo SS, Lee S, Kim JY, Kim SK, Kang KW, Lee JS, Jeong JY and Park SY. Comparison of the accuracy of magnetic resonance imaging and positron emission tomography/computed tomography in the presurgical detection of lymph node metastases in patients with uterine cervical carcinoma: a prospective study. Cancer. 2006; 106:914-922.

22. Choi HJ, Kim SH, Seo SS, Kang S, Lee S, Kim JY, Kim YH, Lee JS, Chung HH, Lee JH and Park SY. MRI for pretreatment lymph node staging in uterine cervical cancer. AJR Am J Roentgenol. 2006; 187:W538-543.

23. Chou H-H, Chang T-C, Yen T-C, Ng K-K, Hsueh S, Ma S-Y, Chang C-J, Huang H-J, Chao A and Wu T-I. Low value of [18F]-fluoro-2-deoxy-D-glucose positron emission tomography in primary staging of early-stage cervical cancer before radical hysterectomy. Journal of clinical oncology. 2006; 24:123-128.

24. Chung HH, Kang SB, Cho JY, Kim JW, Park NH, Song YS, Kim SH and Lee HP. Can preoperative MRI accurately evaluate nodal and parametrial invasion in early stage cervical cancer? Jpn J Clin Oncol. 2007; 37:370-375.

25. Chung HH, Park NH, Kim JW, Song YS, Chung JK and Kang SB. Role of integrated PET-CT in pelvic lymph node staging of cervical cancer before radical hysterectomy. Gynecol Obstet Invest. 2009; 67:61-66.

26. Chung HH, Kang KW, Cho JY, Kim JW, Park NH, Song YS, Kim SH, Chung JK and Kang SB. Role of magnetic resonance imaging and positron emission tomography/ 
computed tomography in preoperative lymph node detection of uterine cervical cancer. Am J Obstet Gynecol. 2010; 203:156 e151-155.

27. Crivellaro C, Signorelli M, Guerra L, De Ponti E, Pirovano C, Fruscio R, Elisei F, Montanelli L, Buda A and Messa C. Tailoring systematic lymphadenectomy in high-risk clinical early stage endometrial cancer: the role of 18F-FDG PET/ CT. Gynecologic oncology. 2013; 130:306-311.

28. Driscoll DO, Halpenny D, Johnston C, Sheehy N and Keogan M. 18F-FDG-PET/CT is of limited value in primary staging of early stage cervical cancer. Abdom Imaging. 2015; 40:127-133.

29. Greco A, Mason P, Leung A, Dische S, McIndoe G and Anderson M. Staging of carcinoma of the uterine cervix: MRI-surgical correlation. Clinical radiology. 1989; 40:401405.

30. Grumbine FC, Rosenshein NB, Zerhouni EA and Siegelman SS. Abdominopelvic computed tomography in the preoperative evaluation of early cervical cancer. Gynecologic oncology. 1981; 12:286-290.

31. Han SS, Lee SH, Kim DH, Kim JW, Park NH, Kang SB and Song YS. Evaluation of preoperative criteria used to predict lymph node metastasis in endometrial cancer. Acta Obstet Gynecol Scand. 2010; 89:168-174.

32. Hawighorst H, Schoenberg SO, Knapstein PG, Knopp MV, Schaeffer U, Essig M and van Kaick G. Staging of invasive cervical carcinoma and of pelvic lymph nodes by high resolution MRI with a phased-array coil in comparison with pathological findings. J Comput Assist Tomogr. 1998; 22:75-81.

33. Hawnaur J, Johnson RJ, Buckley C, Tindall V and Isherwood I. Staging, volume estimation and assessment of nodal status in carcinoma of the cervix: comparison of magnetic resonance imaging with surgical findings. Clinical radiology. 1994; 49:443-452.

34. Henrich W, Fotopoulou C, Fuchs I, Wolf C, Schmider A, Denkert C, Lichtenegger W and Sehouli J. Value of preoperative transvaginal sonography (TVS) in the description of tumor pattern in ovarian cancer patients: results of a prospective study. Anticancer Res. 2007; 27:4289-4294.

35. Horowitz NSnpo, Dehdashti F, Herzog TJ, Rader JS, Powell MA, Gibb RK, Grigsby PW, Siegel BA and Mutch DG. Prospective evaluation of FDG-PET for detecting pelvic and para-aortic lymph node metastasis in uterine corpus cancer. Gynecol Oncol. 2004; 95:546-551.

36. Huang J, Gu M, Su Y, Yang L, Li Y and He H. Use preoperative diffusion weighted MRI imaging and serum CA125 level to predict lymph node metastasis in endometrial cancer. Chinese Journal of Practical Gynecology Obstetrics. 2011; 27:676-679.

37. Husby JA, Reitan BC, Biermann M, Trovik J, Bjørge L, Magnussen IJ, Salvesen ØO, Salvesen HB and Haldorsen IS. Metabolic tumor volume on 18F-FDG PET/CT improves preoperative identification of high-risk endometrial carcinoma patients. Journal of Nuclear Medicine. 2015; 56:1191-1198.

38. Inubashiri E, Hata K, Kanenishi K, Shiota A, Ohno M, Yamamoto Y, Nishiyama Y, Ohkawa M and Hata T. Positron emission tomography with the glucose analog $[\mathrm{F}]-$ fluoro-2-deoxy-D-glucose for evaluating pelvic lymph node metastasis in uterine corpus cancer: comparison with CT and MRI findings. J Obstet Gynaecol Res. 2009; 35:26-34.

39. Janus CL, Mendelson DS, Moore S, Gendal ES, Dotting P and Brodman M. Staging of cervical carcinoma: accuracy of magnetic resonance imaging and computed tomography. Clinical imaging. 1989; 13:114-116.

40. Keller TM, Michel SC, Frohlich J, Fink D, Caduff R, Marincek B and Kubik-Huch RA. USPIO-enhanced MRI for preoperative staging of gynecological pelvic tumors: preliminary results. Eur Radiol. 2004; 14:937-944.

41. Kim SH, Choi BI, Lee HP, Kang SB, Choi YM, Han MC and Kim C-W. Uterine cervical carcinoma: comparison of CT and MR findings. Radiology. 1990; 175:45-51.

42. Kim SH, Choi BI, Han JK, Kim HD, Lee HP, Kang SB, Lee JY and Han MC. Preoperative staging of uterine cervical carcinoma: comparison of CT and MRI in 99 patients. Journal of computer assisted tomography. 1993; 17:633640.

43. Kim SH, Kim SC, Choi BI and Han MC. Uterine cervical carcinoma: evaluation of pelvic lymph node metastasis with MR imaging. Radiology. 1994; 190:807-811.

44. Kim JK, Kim KA, Park BW, Kim N and Cho KS. Feasibility of diffusion-weighted imaging in the differentiation of metastatic from nonmetastatic lymph nodes: Early experience. Journal of Magnetic Resonance Imaging. 2008; 28:714-719.

45. Kim M-h, Kim JK, Lee Y, Park B-W, Lee CK, Kim N, Cho G, Choi HJ and Cho K-S. Diagnosis of lymph node metastasis in uterine cervical cancer: usefulness of computer-aided diagnosis with comprehensive evaluation of MR images and clinical findings. Acta Radiologica. 2011; 52:1175-1183.

46. Kitajima Kkmk-uaj, Murakami K, Yamasaki E, Fukasawa I, Inaba N, Kaji Y and Sugimura K. Accuracy of 18F-FDG $\mathrm{PET} / \mathrm{CT}$ in detecting pelvic and paraaortic lymph node metastasis in patients with endometrial cancer. AJR Am J Roentgenol. 2008; 190:1652-1658.

47. Kitajima K, Suenaga Y, Ueno Y, Kanda T, Maeda T, Takahashi S, Ebina Y, Miyahara Y, Yamada $\mathrm{H}$ and Sugimura K. Value of fusion of PET and MRI for staging of endometrial cancer: comparison with 18 F-FDG contrastenhanced PET/CT and dynamic contrast-enhanced pelvic MRI. European journal of radiology. 2013; 82:1672-1676.

48. Klar M, Meyer PT, Hancke K, Brink I, Orlowska-Volk M, Gitsch G and Denschlag D. Evaluation of FDG-PET for detecting lymph node metastasis in uterine corpus cancer. Anticancer Res. 2010; 30:3787-3790. 
49. Klerkx WM, Veldhuis WB, Spijkerboer AM, van den Bosch MA, Mali WP, Heintz AP, Bipat S, Sie-Go DM, van der Velden J, Schreuder HW, Stoker J and Peeters PH. The value of 3.0Tesla diffusion-weighted MRI for pelvic nodal staging in patients with early stage cervical cancer. Eur J Cancer. 2012; 48:3414-3421.

50. Koplay M, Dogan NU, Erdogan H, Sivri M, Erol C, Nayman A, Karabagli P, Paksoy Y and Celik C. Diagnostic efficacy of diffusion-weighted MRI for pre-operative assessment of myometrial and cervical invasion and pelvic lymph node metastasis in endometrial carcinoma. J Med Imaging Radiat Oncol. 2014; 58:538-546; quiz 648.

51. Li Y and Zhao Z. Value of transvaginal ultrasound in diagnosis of internal iliac lymph nodes metastasis of cavitas pelvis tumor. Journal of Clinical Ultrasound in Medicine. 2011; 13:841-843.

52. Li Y, Zhao Z, Yang J and Liang Y. The Value of Transvaginal Color Doppler Ultrasonography in the Diagnosis of Obturator Lymph Nodes Metastases of Gynecological Pelvic Tumors. Chinese Journal of Practical Gynecology Obstetrics. 2011; 19:918-920.

53. Liao J and Chen Y. Study of diffusion-weighted MR imaging for pelvic lymph node in patients with cervical carcinoma. MD thesis Fujian: Fujian Medical University. 2008.

54. Liu Y, Liu H, Bai X, Ye Z, Sun H, Bai R and Wang D. Differentiation of metastatic from non-metastatic lymph nodes in patients with uterine cervical cancer using diffusion-weighted imaging. Gynecologic oncology. 2011; 122:19-24.

55. Lv K. The application value of $18 \mathrm{~F}-\mathrm{FDG}$ PET/CT in the clinical evaluation of patients with cervical cancer. 2015.

56. Ma Y, Bai P, Dai J, Zhang W and Zhu Z. [Evaluation of CT scanning in detecting pelvic lymph node metastasis in uterine cervix carcinoma]. Zhonghua $\mathrm{Fu}$ Chan Ke Za Zhi. 2009; 44:422-425.

57. Matsukuma K, Tsukamoto N, Matsuyama T, Ono M and Nakano H. Preoperative CT study of lymph nodes in cervical cancer - its correlation with histological findings. Gynecologic oncology. 1989; 33:168-171.

58. Nakamura K, Kodama J, Okumura Y, Hongo A, Kanazawa $\mathrm{S}$ and Hiramatsu Y. The SUVmax of $18 \mathrm{~F}-\mathrm{FDG}$ PET correlates with histological grade in endometrial cancer. International Journal of Gynecological Cancer. 2010; 20:110-115.

59. Nakamura K, Hongo A, Kodama J and Hiramatsu Y. The measurement of SUVmax of the primary tumor is predictive of prognosis for patients with endometrial cancer. Gynecologic oncology. 2011; 123:82-87.

60. Nogami Y, Banno K, Irie H, Iida M, Kisu I, Masugi Y, Tanaka K, Tominaga E, Okuda S and Murakami K. The efficacy of preoperative positron emission tomographycomputed tomography (PET-CT) for detection of lymph node metastasis in cervical and endometrial cancer: clinical and pathological factors influencing it. Japanese journal of clinical oncology. 2014:hyu161.

61. Ozalp S, Yalcin OT, Polay S, Aslan N, Vardareli E and Adapinar B. Diagnostic efficacy of the preoperative lymphoscintigraphy, Ga-67 scintigraphy and computed tomography for detection of lymph node metastasis in cases with ovarian or endometrial carcinoma. Acta Obstet Gynecol Scand. 1999; 78:155-159.

62. Park JY, Kim EN, Kim DY, Suh DS, Kim JH, Kim YM, Kim YT and Nam JH. Comparison of the validity of magnetic resonance imaging and positron emission tomography/computed tomography in the preoperative evaluation of patients with uterine corpus cancer. Gynecol Oncol. 2008; 108:486-492.

63. Picchio M, Mangili G, Gajate AMS, De Marzi P, Spinapolice EG, Mapelli P, Giovacchini G, Sigismondi C, Vigano R and Sironi S. High-grade endometrial cancer: value of $[18 \mathrm{~F}] \mathrm{FDG} \mathrm{PET} / \mathrm{CT}$ in preoperative staging. Nuclear medicine communications. 2010; 31:506-512.

64. Rechichi Ggrgc, Galimberti S, Oriani M, Perego P, Valsecchi MG and Sironi S. ADC maps in the prediction of pelvic lymph nodal metastatic regions in endometrial cancer. Eur Radiol. 2013; 23:65-74.

65. Reinhardt MJ, Ehritt-Braun C, Vogelgesang D, Ihling C, Hogerle S, Mix M, Moser E and Krause TM. Metastatic lymph nodes in patients with cervical cancer: detection with MR imaging and FDG PET. Radiology. 2001; 218:776-782.

66. Rizzo S, Calareso G, Maccagnoni S, Angileri SA, Landoni F, Raimondi S, Pasquali E, Lazzari R and Bellomi M. Preoperative MR evaluation of features that indicate the need of adjuvant therapies in early stage cervical cancer patients. A single-centre experience. Eur J Radiol. 2014; 83:858-864.

67. Sawicki W, Spiewankiewicz B, Stelmachow J and Cendrowski K. The value of ultrasonography in preoperative assessment of selected prognostic factors in endometrial cancer. Eur J Gynaecol Oncol. 2003; 24:293298.

68. Signorelli M, Guerra L, Buda A, Picchio M, Mangili G, Dell'Anna T, Sironi S and Messa C. Role of the integrated FDG PET/CT in the surgical management of patients with high risk clinical early stage endometrial cancer: detection of pelvic nodal metastases. Gynecol Oncol. 2009; 115:231235.

69. Signorelli M, Guerra L, Pirovano C, Crivellaro C, Fruscio R, Buda A, Cuzzucrea M, Elisei F, Ceppi L and Messa C. Detection of nodal metastases by $18 \mathrm{~F}-\mathrm{FDG}$ PET/CT in apparent early stage ovarian cancer: a prospective study. Gynecol Oncol. 2013; 131:395-399.

70. Sironi S, Buda A, Picchio M, Perego P, Moreni R, Pellegrino A, Colombo M, Mangioni C, Messa C and Fazio F. Lymph Node Metastasis in Patients with Clinical EarlyStage Cervical Cancer: Detection with Integrated FDG PET/CT 1. Radiology. 2006; 238:272-279.

71. Subak LL, Hricak H, Powell CB, Azizi L and Stern JL. 
Cervical carcinoma: computed tomography and magnetic resonance imaging for preoperative staging. Obstetrics \& Gynecology. 1995; 86:43-50.

72. Sufian SN, Masroor I, Mirza W, Hussain Z, Hafeez S and Sajjad Z. Accuracy of magnetic resonance imaging in pretreatment lymph node assessment for gynecological malignancies. Asian Pac J Cancer Prev. 2014; 15:47054709.

73. Suga T, Nakamoto Y, Saga T, Higashi T, Hamanaka Y, Tatsumi M, Hayashida K, Hara T, Konishi I and Fujii S. Clinical value of FDG-PET for preoperative evaluation of endometrial cancer. Annals of nuclear medicine. 2011; 25:269-275.

74. Sugiyama T, Nishida T, Ushijima K, Sato N, Kataoka A, Imaishi K, Fujiyoshi K and Yakushiji M. Detection of lymph node metastasis in ovarian carcinoma and uterine corpus carcinoma by preoperative computerized tomography or magnetic resonance imaging. J Obstet Gynaecol (Tokyo 1995). 1995; 21:551-556.

75. Suzuki R, Miyagi E, Takahashi N, Sukegawa A, Suzuki A, Koike I, Sugiura K, Okamoto N, Inoue T and Hirahara F. Validity of positron emission tomography using fluoro-2deoxyglucose for the preoperative evaluation of endometrial cancer. Int J Gynecol Cancer. 2007; 17:890-896.

76. Teng F, Zhang YF, Wang YM, Yu J, Lang X, Tian WY, Jiang CX and Xue FX. Contrast-enhanced MRI in preoperative assessment of myometrial and cervical invasion, and lymph node metastasis: diagnostic value and error analysis in endometrial carcinoma. Acta Obstet Gynecol Scand. 2015; 94:266-273.

77. Unger J, Ivy J, Ramaswamy M, Charrier A and Connor P. Whole-body [18F] fluoro-2-deoxyglucose positron emission tomography scan staging prior to planned radical hysterectomy and pelvic lymphadenectomy. International Journal of Gynecological Cancer. 2005; 15:1060-1064.

78. van Engelshoven J, Versteege C, Ruys J, De Haan J and Sanches H. Computed tomography in staging untreated patients with cervical cancer. Gynecologic and obstetric investigation. 1984; 18:289-295.

79. Vas W, Wolverson M, Freel J, Salimi Z and Sundaram M. Computed tomography in the pretreatment assessment of carcinoma of the cervix. Journal of Computed Tomography. 1985; 9:359-368.

80. Vijaykumar DK, Prahlad S and Chaturvedi HK. Ultrasound evaluation of pelvic nodes in cervical carcinoma. Eur J Gynaecol Oncol. 1995; 16:224-227.

81. Walsh JW and Goplerud DR. Prospective comparison between clinical and CT staging in primary cervical carcinoma. American Journal of Roentgenology. 1981; 137:997-1003.

82. Wang $\mathrm{T}$ and Zhai J. Diagnostic value of PET/CT for lymph node metastasis of ovarian malignant tumor. Chinese Journal of Clinical Research. 2015; 28:1436-1438.

83. Wright JD, Dehdashti F, Herzog TJ, Mutch DG, Huettner
PC, Rader JS, Gibb RK, Powell MA, Gao F, Siegel BA and Grigsby PW. Preoperative lymph node staging of early-stage cervical carcinoma by [18F]-fluoro-2-deoxyD-glucose-positron emission tomography. Cancer. 2005; 104:2484-2491.

84. Xue H-d, Li S, Sun F, Sun H-y, Jin Z-y, Yang J-x and Yu M. Clinical application of body diffusion weighted MR imaging in the diagnosis and preoperative $\mathrm{N}$ staging of cervical cancer. Chinese Medical Sciences Journal. 2008; 23:133-137.

85. Yang WT, Cheung TH, Ho SS, Yu MY and Metreweli C. Comparison of laparoscopic sonography with surgical pathology in the evaluation of pelvic lymph nodes in women with cervical cancer. AJR Am J Roentgenol. 1999; 172:1521-1525.

86. Yang WT, Lam WW, Yu MY, Cheung TH and Metreweli C. Comparison of dynamic helical CT and dynamic MR imaging in the evaluation of pelvic lymph nodes in cervical carcinoma. AJR Am J Roentgenol. 2000; 175:759-766.

87. Yeh LS, Hung YC, Shen YY, Kao CH, Lin CC and Lee CC. Detecting para-aortic lymph nodal metastasis by positron emission tomography of $18 \mathrm{~F}$-fluorodeoxyglucose in advanced cervical cancer with negative magnetic resonance imaging findings. Oncol Rep. 2002; 9:1289-1292.

88. Yoo SC, Kim WY, Yoon JH, Kim HY, Lee EJ, Chang SJ, Chang KH and Ryu HS. Accuracy of preoperative magnetic resonance imaging in assessing lymph node metastasis and myometrial invasion in patients with uterine cancer. Eur J Gynaecol Oncol. 2009; 30:167-170.

89. Zhang W, Zhang J, Yang J, Xue H, Cao D, Huang H, Wu M, Cui Q, Chen J, Lang J and Shen K. The role of magnetic resonance imaging in pretreatment evaluation of early-stage cervical cancer. Int J Gynecol Cancer. 2014; 24:1292-1298.

90. Siegel RL, Miller KD and Jemal A. Cancer statistics, 2016. CA Cancer J Clin. 2016; 66:7-30.

91. Neubauer NL and Lurain JR. The role of lymphadenectomy in surgical staging of endometrial cancer. International journal of surgical oncology. 2011; 2011.

92. Van Bommel P, Van Lindert A, Kock H, Leers W and Neijt J. A review of prognostic factors in early-stage carcinoma of the cervix (FIGO IB and II A) and implications for treatment strategy. European Journal of Obstetrics \& Gynecology and Reproductive Biology. 1987; 26:69-84.

93. Chen Y, Zhang L, Tian J, Ren X and Hao Q. Combining the negative lymph nodes count with the ratio of positive and removed lymph nodes can better predict the postoperative survival in cervical cancer patients. Cancer cell international. 2013; 13:1.

94. Boronow R, Morrow C, Creasman W, Disaia P, Silverberg $\mathrm{S}$, Miller A and Blessing J. Surgical staging in endometrial cancer: clinical-pathologic findings of a prospective study. Obstetrics \& Gynecology. 1984; 63:825-832.

95. Creasman WT, Morrow CP, Bundy B, Homesley HD, Graham J and Heller P. Surgical pathologic spread patterns 
of endometrial cancer. A gynecologic oncology group study Cancer. 1987; 60:2035-2041.

96. DiSaia PJ, Morrow CP, Boronow R, Creasman W and Mittelstaedt L. Endometrial sarcoma: lymphatic spread pattern. American Journal of Obstetrics \& Gynecology. 1978; 130:104-105.

97. Scheidler J, Hricak H, Kyle KY, Subak L and Segal MR. Radiological evaluation of lymph node metastases in patients with cervical cancer: a meta-analysis. Jama. 1997; 278:1096-1101.

98. Shen G, Zhou H, Jia Z and Deng H. Diagnostic performance of diffusion-weighted MRI for detection of pelvic metastatic lymph nodes in patients with cervical cancer: a systematic review and meta-analysis. The British journal of radiology. 2015; 88:20150063.

99. Chang M-C, Chen J-H, Liang J-A, Yang K-T, Cheng K-Y and Kao C-H. 18F-FDG PET or PET/CT for detection of metastatic lymph nodes in patients with endometrial cancer: a systematic review and meta-analysis. European journal of radiology. 2012; 81:3511-3517.

100. Rohren EM, Turkington TG and Coleman RE. Clinical applications of PET in oncology 1. Radiology. 2004; 231:305-332.

101. Y L and Z Z. Value of transvaginal ultrasound in diagnosis of internal iliac lymph nodes metastasis of cavitas pelvis tumor. Journal of Clinical Ultrasound in Medicine. 2011; 13:841-843.
102. Su Z, Duan Z, Pan W, Wu C, Jia Y, Han B and Li C. Predicting extracapsular spread of head and neck cancers using different imaging techniques: a systematic review and meta-analysis. International journal of oral and maxillofacial surgery. 2016; 45:413-421.

103. de Vet HCW EA, Riphagen II, Aertgeerts B, Pewsner D. (2008). Chapter 7: Searching for Studies. Cochrane Handbook for Systematic Reviews of Diagnostic Test Accuracy Version 04: The Cochrane Collaboration.).

104. Whiting PF, Rutjes AW, Westwood ME, Mallett S, Deeks JJ, Reitsma JB, Leeflang MM, Sterne JA and Bossuyt PM. QUADAS-2: a revised tool for the quality assessment of diagnostic accuracy studies. Annals of internal medicine. 2011; 155:529-536.

105. Li C, Sheng S, Men Y, Sun H, Xia H and Li L. Emission Computed Tomography for the Diagnosis of Mandibular Invasion by Head and Neck Cancers: A Systematic Review and Meta-Analysis. Journal of Oral and Maxillofacial Surgery. 2015; 73:1875. e1871-1875. e1811.

106. Li C, Yang W, Men Y, Wu F, Pan J and Li L. Magnetic resonance imaging for diagnosis of mandibular involvement from head and neck cancers: a systematic review and metaanalysis. PloS one. 2014; 9:e112267.

107. Leeflang MM, Deeks JJ, Gatsonis C and Bossuyt PM. Systematic reviews of diagnostic test accuracy. Annals of internal medicine. 2008; 149:889-897. 